\title{
PRELIMINARY RESULTS OF THE MARKING OF WHALES BY THE DISCOVERY COMMITTEE
}

\author{
By George W. Rayner
}

$\mathrm{F}$ RON the outset of its investigations, the Discovery Committee has considered whale marking to be a method of considerable importance in approaching many of the problems to be solved in a study of the life-history of whales. It was, however, found difficult to design an efficient mark, and it was not until 1932 that a suitable form was produced. The mark then adopted consists of a stainless steel tube fired at the whale by means of a 12-bore gun ; it is designed to penetrate the blubber and to remain embedded until the whale is captured and dismembered by the whalers. 'This form of mark was given a trial during the whaling season of $1932-33$ and the results forthcoming during the ensuing year were so encouraging that an extensive programme of whale marking was planned and carried out during 1931-35 and the three following seasons.

In 1934 the Committee's ship, the R.R.S. William Scoresby, was commissioned solely for whale marking purposes and spent the whole of the 1934-35 scason on the Antarctic whaling grounds lying eastwards of the Greenwich meridian and extending almost as far as the longitude of Western Australia. At the same time a hired whale catcher operated for about six weeks in the middle of the season from South Georgia, where the area covered was much more restricted. This programme, with the William Scoresby working for the whole season on the pelagic grounds to the cast and the whale catcher covering a small area around South Georgia in an intensive manner, was repeated during the following two seasons, 1935-36 and 1936-37. In 1937-38 the programme was modified ; only the William Scoresby operated and her work was planned to fill in gaps and to amplify, in the light of results already obtained, that accomplished previously. She commenced earlier in the season to the north of South Georgia and worked eastwards to the Greenwich meridian, then westwards again along the ice edge before the whaling season commenced. She then marked whales across the mouth of the Weddell Sea and made two incursions into the Bellingshausen Sea.

On Chart $I$ is depicted the distribution and intensity of the marking carried out since 1932-33. There is an area of intensive marking around South Georgia, with a small area around the Shag
Rochs, 120 miles westward of the northern point of South Georgia, where very many whales-more than six hundred-have been marked. There are further two extensive areas in which relatively large numbers of whales have been marked, one off Queen Mary Land ( $85^{\circ}$ E. $-95^{\circ}$ E.), and a second off Enderby Land ( $15^{\circ} \mathrm{E} .-50^{\circ} \mathrm{E}$.). In addition, whales in lesser numbers have been marked over an immense area connecting and extending the regions of more intensive marking; on the chart the continuous longitudinal lines show where this marking has been relatively dense, the broken lines where it has been scattered. The areas of more intensive marking correspond to some extent with the grounds mostly frequented by the whalers.

The whales supporting the Antaretic whaling industry are, in order of their importance, Blue, Fin and Humpback, the last being relatively unimportant. The majority of the Humpback whales marked have been found off Queen Mary Land. Whales marked around South Georgia have been predominantly Fin, and in the area around the Shag Rocks exclusively so.

Numerically the results are given in the following table :

\begin{tabular}{|l|c|c|c|}
\hline Species & No. marked & \multicolumn{2}{|c|}{ Returns } \\
& & No. & $\%$ \\
\hline Blue & 668 & 33 & 4.94 \\
Fin & 3902 & 118 & 3.02 \\
Hump & 548 & 30 & 6.59 \\
Sei & 28 & - & - \\
Right & 8 & - & - \\
\hline Spcrm & 56 & - & - \\
\hline Totali & 5210 & 187 & - \\
\hline
\end{tabular}

In addition to the three commercially important species, it will be seen that an insignificant number of the less important and rarer species have also been marked. The number of marked whales reported as captured is 187, and these have been taken at intervals after marking varying from a few hours to fifteen hundred days.

Since it is not certain how many inarks drop out or are missed by the whalers, the percentage figures are not an absolute indication of the percentage of marked whales killed, but they are very instructive as to the relative effect of whaling on 


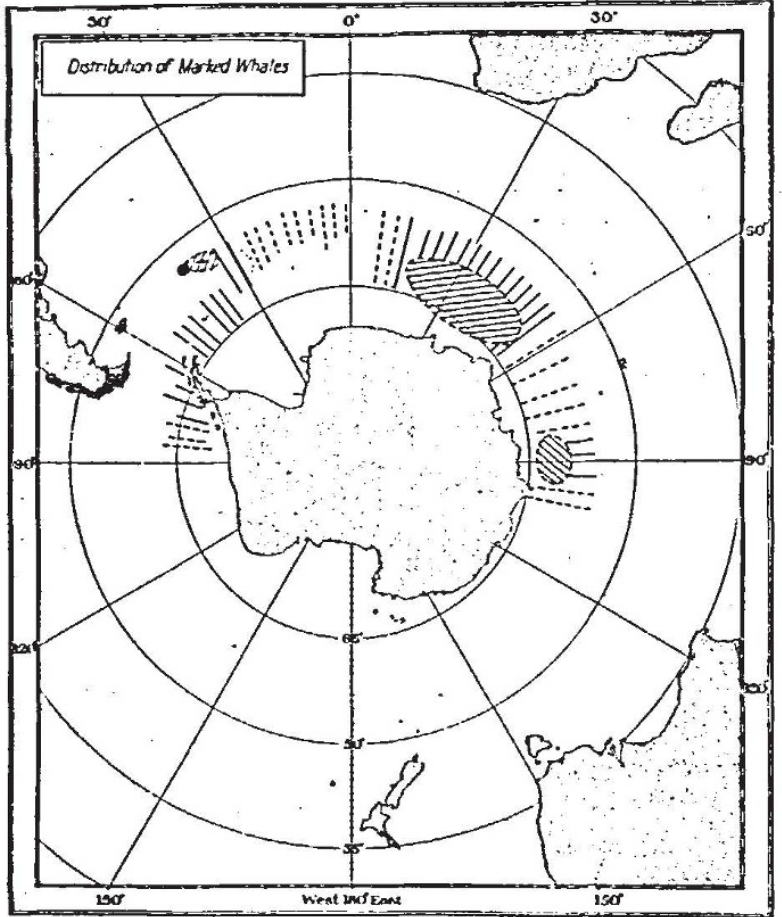

Chart I.

the stocks of the different species. The Blue whale is the species most eagerly sought after by the whalers, although the Fin whale is far commoner. The percentage figures show how the stock of Blue whales is being depleted at a considerably faster rate than that of Fins-5 per cent of the marked Blue whales have been reported killed as opposed to 3 per cent of the marked Fin whales. The percentage of marked Humpbacks taken compared with the figures for the other two species is striking, and it is evident that this whale is being killed off at a surprisingly faster rate than the other two. Soon after whale marking commenced, whaling during the southern winter was resumed off the north-west coast of Australia. This fishery is based on Humpbacks and considerable numbers were taken. Marks recovered

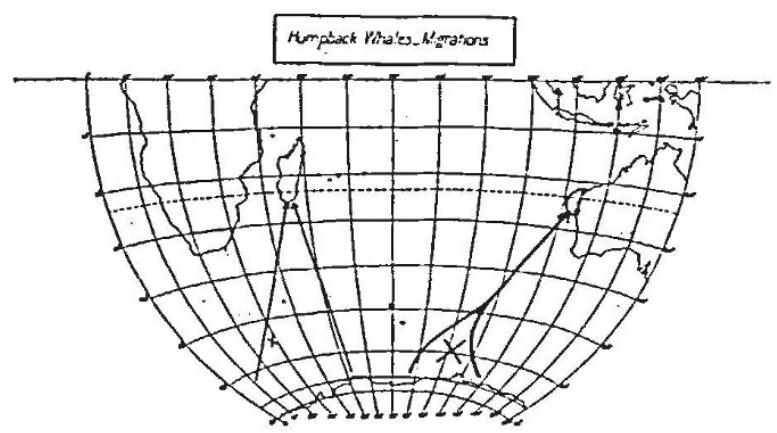

Chart II. showed that these whales were of the same stock as those marked in Antarctic waters off Queen Mary Land (see Chart II). This stock of whales was, therefore, exposed to a double persecution which accounts for the comparatively high percent. age figure of returned marks. Still more recently whaling, again exclusively based on Humpbacks, has broken out during the winter season to the south of Madagascar. This double persecution of Humpback whales, which their habits render particularly easy, cannot fail to have a very marked effect on the comparatively small stock, which is bearing a burden relatively more than double that of the Fin whale stock and considerably higher than that of the Blue stock, already regarded as overtaxed.

The marks recovered have yielded a great deal of information on the movements and migrations of the three commercially important species. Very little indeed had been known previously about the wanderings of whales, and what has been conjectured has rested almost wholly on circumstantial and indirect evidence. The recovered marks demonstrate two main general features of whale movement, complementary or contradictory in character as one may care to consider them. On one hand, whales return to the same part of the Antarctic season by season on regular tracks of migration-they may be said to have a strong homing instinct. On the other hand, they tend to spread around the Antarctic from one region to

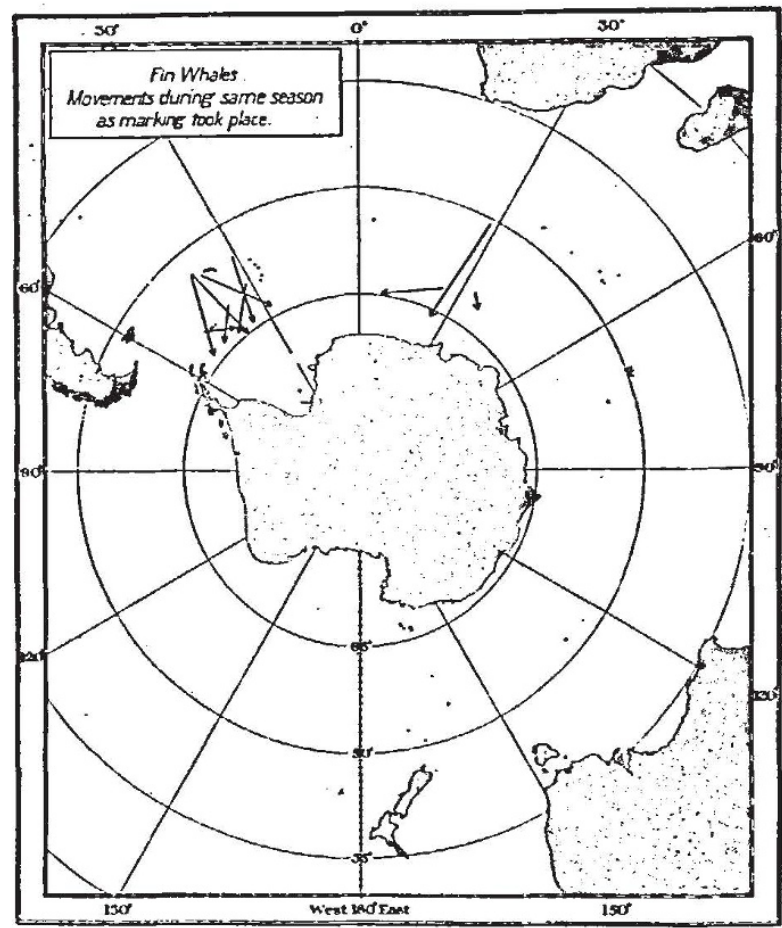

Chart III. 
another, a form of movement going on slowly and gradually and so far only demonstrable among Blues and Fins. One might say that, among the general body of whales keeping to their regular channels of movement, a few are affected with a wanderlust leading them to seek new oceanic pastures and fresh companions.

On the accompanying charts the general trends of movement and migration are indicated by the arrows, the crosses show places where whales have been taken very near the position where they were marked. Possibly more was known about the migrations of the Humpback whales than of any other species, and a north and south migration along the western coast of Australia has been conjectured for some time past. Marking has confirmed this and has demonstrated almost the full course of this migration. Humpback whales marked in the Antarctic have been taken in the southern winter off the north-west coast of Australia after intervals up to three and a half years, whilst they have appeared in the southern summer on the Antarctic grounds near Queen Mary Land one, two and three years after marking. One may confidently say there is an annual north and south migration of Humpback whales along the track shown on Chart II. In the western part of the Indian Ocean a similar north and south migration evidently exists between the Antarctic and the region of Madagascar. There is shown the return to the same area of the Antarctic and the recovery

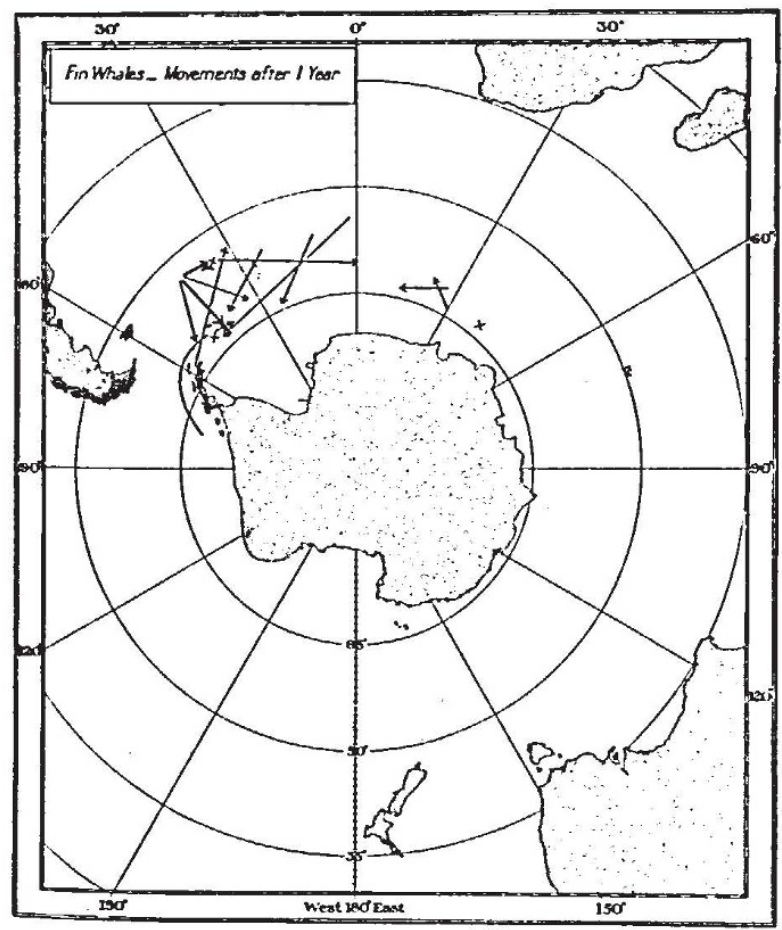

Chart IV.

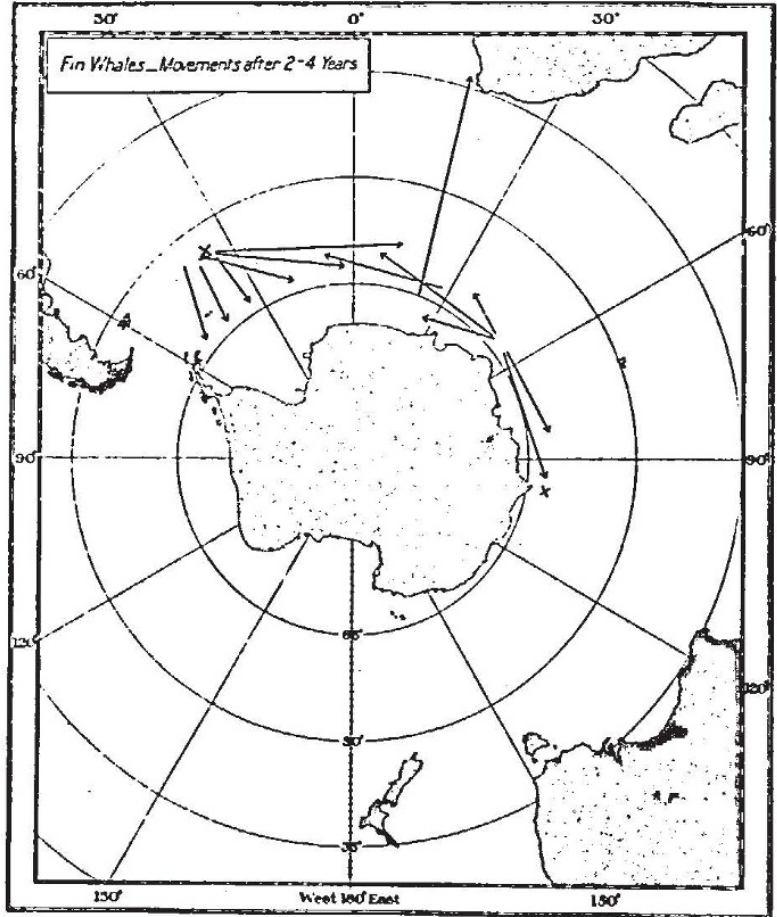

Chart V.

in the tropics during the southern winter. It is most noteworthy that there has been no interchange of Humpbacks between these two regions.

The movements of Fin and Blue whales have been plotted on the accompanying charts according to the time elapsing between marking and capture. Chart III gives the movements of Fin whales during the course of the whaling season, and it shows a general movement southwards towards the edge of the pack ice. A number of Fin whales marked around South Georgia have been taken there during the same season, but never after an interval longer than a few days, so one may consider Fin whales found in these waters to be migrating whales. Further, none of the large numbers of Fin whales marked near the Shag Rocks has been taken the same season by the South Georgia whalers, so there can be little easterly movement here during the season. There is strong evidence that there are regular tracks along which different bodies of Fin whales move on their migrations southward, and it is probable that these tracks may shift a little from season to season.

The movements of Fin whales after a year's time are shown on Chart IV. There has been in many places a return to the same place as marking took place. Further, some arrows show movements which mean essentially a return to the same area both in the east and in the South Georgia - Weddell 


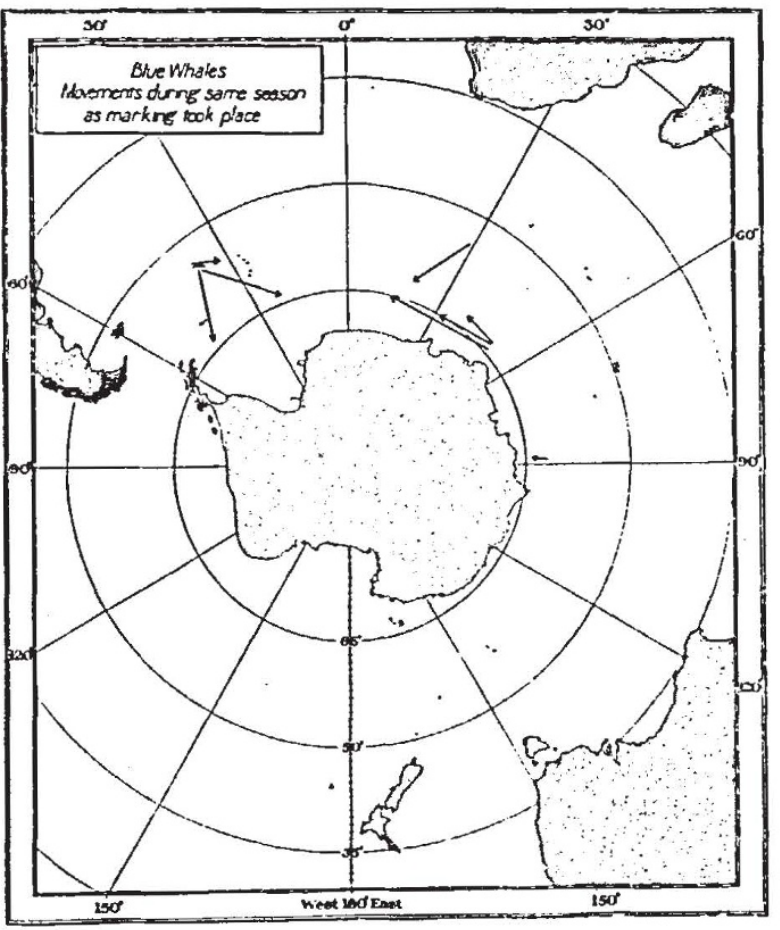

Chart VI.

Sea region. Whales marked around the Shag Rocks have turned up in force near South Georgia and many have been taken to the south again, evidently repeating their movements of the previous year. But wider movements are to be seen, indicating the beginning of spreading. Whales have come into the Scotia Sea area from regions as far apart as the Bellingshausen Sea and the neighbourhood of Bouret Island, whilst a considerable movement outwards towards the east has taken place.

After longer periods, Chart $V$, the same description holds good, but the spreading movement is gathering force. There is still a return to the old grounds, but whales have spread outwards from the Enderby Land region eastwards and west. wards, and the eastward movement from South Georgia has progressed farther. There are now links connecting more than $180^{\circ}$ of longitude, but this movement around the Antarctic may be likened to a relay race in which no individual com. petitor completes the whole course; in fact, it may be suggested that a complete circumnavigation of the continent may take more than a single generation. The significance of this is that whilst the Fin whales of the Antarctic remain specifically one stock, economically several distinct local stocks may be recognized.

One marked Fin whale has been taken at Saldanha Bay, South Africa, after $2 \frac{1}{2}$ years, and this is the first direct evidence of the migration of Fin whales from the Antarctic towards the tropics.
This whale is of particular interest, for when marked it was logged as a calf accompanying its mother.

The movements of Blue whales are in many respects very similar to those of Fin whales, but the picture is not so clear. Around Sonth Georgia many marked Blue whales have been taken the same season as they were marked, but never after an interval longer than a week, so Blue whales found here must be on the move and do not remain long in the vicinity of the island. Their general movement is southerly and to the west or east (Chart VI). This same general southerly movement is shown on the grounds to the east, but off Enderby Land there is strong evidence of a definite westward moving stream of Blue whales.

After one year, Chart VII, there are returns to the same area as was visited the previous season, but there is also considerable spreading. Enderby Land whales now show considerable movement to the east which may be considered complementary to their westward movements during the summer. After longer periods of time the spreading movements shown are actually less than those for the period of about twelve months, but throughout the homing instinct is well maintained; it is easy to see that mixing between the different regions is going on quite slowly, although it is sufficient for the identical specific characteristics to be retained throughout the whole population.

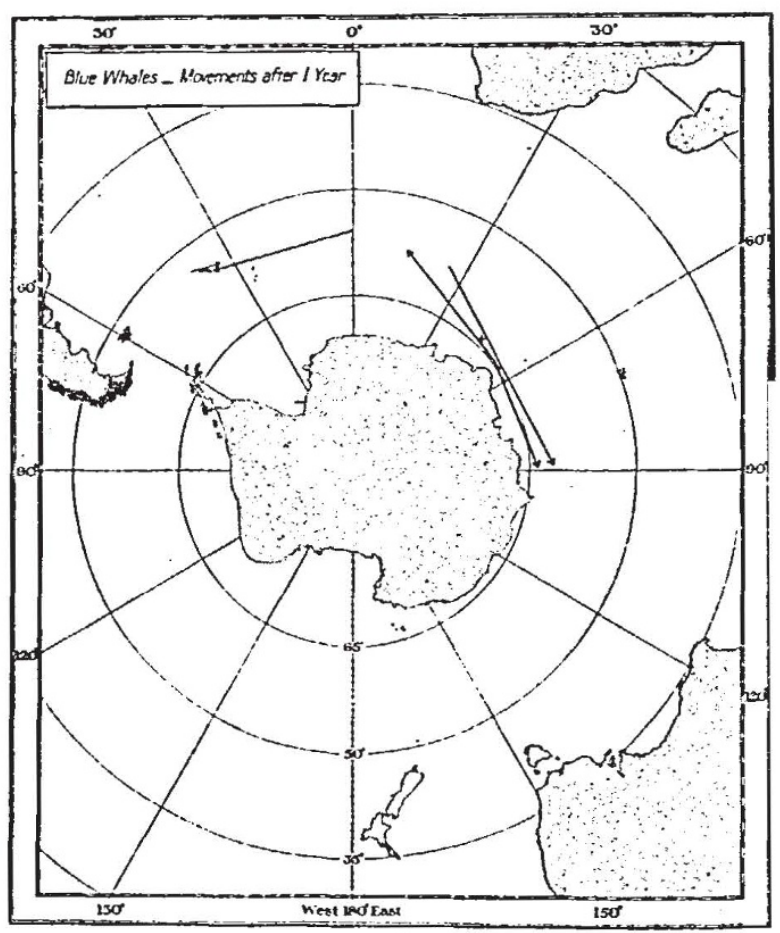

Chart Vif. 